\title{
MUJER Y REPUBLICANISMO EN BILBAO
}

\author{
Jon Penche González \\ Universidad del País Vasco
}

\section{RESUMEN}

En este artículo pretendemos analizar la evolución del papel que la mujer tuvo dentro del movimiento republicano bilbaíno entre 1868 y 1937, desde un estatus de mera acompañante a otro de correligionaria, a la par que nos detenemos en el estudio de sus formas de sociabilidad.

PALABRAS CLAVE: republicanismo, mujer, Bilbao

\begin{abstract}
In this article we try to analyze the evolution of the role that the woman had inside the republican movement from Bilbao between 1868 and 1937, from a status of mere accompanist to other one of colleague, besides that we detain in the study of their forms of sociableness.
\end{abstract}

KEY WORDS: republicanism, woman, Bilbao 


\section{Introducción}

La participación de la mujer en el movimiento republicano se produjo por primera vez en España durante el Sexenio Democrático. En esta época, algunas mujeres republicanas participaron en manifestaciones a favor de la libertad religiosa o de apoyo a las medidas anticlericales de sus correligionarios ${ }^{1}$, a la vez que se crearon las primeras asociaciones femeninas republicanas. Las actividades de estas primeras agrupaciones estaban encaminadas, por un lado, a conseguir la emancipación de la mujer, entendida en este momento como la capacitación intelectual y la independencia económica, esto es, el acceso a la educación, a la propiedad o a un empleo convenientemente remunerado, y por otro, a socorrer y asistir al elemento obrero².

A estas pioneras en la movilización republicana por la emancipación femenina las siguieron en la Restauración otras vinculadas con el librepensamiento que operaron desde presupuestos laicistas y anticlericales. Éstas propugnaban la emancipación femenina y la regeneración social como objetivos fundamentales de su actividad pública, y consideraban que el acceso de las mujeres a una mayor educación les permitiría liberarse de la influencia clerical, situación que únicamente se daría con la implantación de una sociedad laica y republicana ${ }^{3}$.

Este feminismo laicista se agrupó en España en torno a tres núcleos librepensadores: el catalán, en torno a la Sociedad Autónoma de Mujeres, luego denominada Sociedad Progresiva Femenina; el valenciano, con la Asociación General Femenina a la cabeza; y el andaluz, que tenía en la Federación Malagueña de Sociedades de Resistencia, la logia gaditana Hijas de la Regeneración, y la Unión Femenina de Huelva a sus principales agrupaciones ${ }^{4}$. Sus miembros eran mujeres con una amplia formación (escritoras, periodistas o maestras de escuelas laicas) en cuyo pensamiento confluían las ideas republicanas, laicistas, obreristas y feministas, y que desarrollaron su actividad reivindicativa a través de la prensa, los mítines, las conferencias, y los congresos de librepensamiento. Además, su vinculación partidaria con el republicanismo les dio la oportunidad de que sus ideas sobre la importancia de la educación para la emancipación femenina llegaran a un público más amplio.

El modelo feminista laico se agotó como vínculo aglutinante para el asociacionismo republicano femenino en torno a los años de la Primera Guerra Mundial, una vez que el conflicto clericalismo/anticlericalismo desapareció de la primera plana del deba-

1 SALOMÓN CHÉLIZ, Ma Pilar: "Laicismo, género y religión. Perspectivas historiográficas”, Ayer, 61 (2006), p. 296.

2 Gloria Espigado nos habla de la creación de clubes femeninos afirmando que en ninguno de ellos se puso interés en reclamar el derecho al sufragio femenino, centrando únicamente su actividad en la educativa y la asistencial. Fuente: ESPIGADO TOCINO, Gloria: "Mujeres radicales: utópicas, republicanas e internacionalistas en España (1848-1874)”, Ayer, 60 (2005), pp. 15-43.

3 SALOMÓN CHÉLIZ, Ma Pilar: “¿Espejos invertidos? Mujeres clericales, mujeres anticlericales”, en Arenal. Revista de Historia de las mujeres, 11-2 (2004), p. 89 y 97.

4 Los tres núcleos femeninos librepensadores son estudiados en RAMOS PALOMO, Ma Dolores: "La cultura societaria del feminismo librepensador en España (1895-1918)", en A. QUILES FAZ y T. SAURET GUERRERO (coords.): Prototipos e imágenes de la mujer en los siglos XIX y XX, Málaga, Universidad de Málaga, 2002, pp. 90-97. 
te político ${ }^{5}$. A partir de la década de los veinte, el principio por el cual las mujeres republicanas sostuvieron sus movilizaciones fue el sufragismo y la igualdad de derechos civiles, políticos y sociales con los hombres, dejando en un segundo plano al principio laico y sus reivindicaciones educativas ${ }^{6}$.

Con ese fin, se crearon nuevas asociaciones femeninas republicanas: la Asociación Nacional de Mujeres Españolas en 1920, el Lyceum Club en 1926, el Patronato de la Mujer y la Unión Republicana Femenina en 1931, o la Asociación Femenina de Educación Cívica en 1932, entre otras muchas. Sus integrantes, nos dice Pilar Salomón, constituyeron una élite femenina reducida pero muy activa en la vida cultural y política española, comprometida con el reformismo republicano y vinculada al institucionismo, que llevaba años demandando que las mujeres fueran ciudadanas con iguales derechos políticos, civiles y sociales que los hombres ${ }^{7}$.

\section{La vinculación de la mujer con el republicanismo en Bilbao}

En la capital vizcaína, comenzamos a tener noticias de la participación femenina en actos republicanos a partir de 1903, pues desde el Sexenio Democrático hasta entonces los periódicos no nos ofrecen indicio alguno de la colaboración de la mujer en tareas del partido ${ }^{8}$. Una excepción debemos hacer constar en este panorama: la invitación que desde la Sociedad Cooperativa de Consumos, vinculada al Partido Republicano Federal, se hizo en 1870 a las mujeres para que participasen en la misma y pudiesen dar así el primer paso para su emancipación ${ }^{9}$.

En las dos primeras décadas del siglo XX, como decimos, el diario El Liberal nos ofrece las primeras pistas de la presencia femenina en actividades republicanas. Esta se centraba fundamentalmente en la asistencia a los actos y eventos organizados por el Casino Republicano o el Círculo Republicano para gestionar el ocio de sus socios y sus familias, como conferencias, kermesses ${ }^{10}$, bailes o veladas. De esta forma, las mujeres se encargaron, por ejemplo, de la venta de papeletas para la kermesse anual navideña o de confeccionar banderas republicanas, tareas que frecuentemente

\footnotetext{
5 Para profundizar más sobre el tema del feminismo laico, consultar RAMOS PALOMO, Ma Dolores: “La República de las librepensadoras (1890-1914): laicismo, emancipismo, anticlericalismo”, Ayer, 60 (2005), pp. 45-74.

6 Esta transición del movimiento laicista al sufragista se refleja perfectamente en FAGOAGA, Concha: "La herencia laicista del movimiento sufragista en España, en A. AGUADO (coord.): Las mujeres ante la historia y la sociedad contemporánea, Valencia, Generalitat Valenciana, 1999, pp. 91-111.
}

7 SALOMÓN CHÉLIZ, Ma Pilar: “Las mujeres en la cultura política republicana: religión y anticlericalismo”, Historia Social, 53 (2005), p. 114.

8 Aquí debemos puntualizar que las colecciones de los periódicos republicanos bilbaínos del último cuarto del XIX se encuentran perdidas, por lo que esta percepción está basada en la consulta de diarios locales de distinta índole.

9 Irurac-Bat, (11-03-1870). Sobre la Sociedad Cooperativa de Consumos de Bilbao en 1870 consultar URQUIJO GOITIA, Mikel: “La primera experiencia cooperativa vasca (Bilbao, 1870)”, Letras de Deusto, 101 (2003), pp. 159-171.

10 La kermesse o kermés era una fiesta en la que se conjugaba el desarrollo de veladas musicales, bailes, fiestas, rifas y concursos con un fin económico benéfico. En el caso del republicanismo bilbaíno los fines eran recaudar fondos para realizar obras en el Casino, coadyuvar a la instalación de escuelas laicas, o simplemente engrosar las arcas del partido. 
eran recompensadas por el centro republicano en cuestión con la celebración de bailes y veladas en su honor y entregas de regalos. Asimismo los casinos republicanos bilbaínos animaban a la participación femenina en los bailes en familia o en los bailes extraordinarios que se organizaban con motivo de las fiestas de carnavales o de la Villa con el obsequio de regalos o ramos de flores. La presencia femenina en estos actos era destacada en la prensa con frases como el sexo femenino asistió numerosamente o se va a organizar un baile en el Casino a petición de bellas y simpáticas señoritas, las cuales reflejaban claramente que el estatus de la mujer dentro del republicanismo bilbaíno no llegaba al del hombre, pues este era tratado como correligionario. Sólo de forma muy ocasional las mujeres tomaban la palabra en alguna reunión republicana, como cuando con motivo del aniversario de la Primera República de 1905, una de las treinta muchachas asistentes al banquete conmemorativo tomó la palabra en el turno de discursos ${ }^{11}$.

Por otra parte, ¿cuál fue la percepción que el elemento masculino tuvo del papel de la mujer dentro del republicanismo bilbaíno? En primer lugar combatían la influencia que el clero ejercía en las mujeres, a las que se tachaba de principal colaborador del clericalismo, y se atacaba la figura del confesor:

La mujer tiene poco que agradecer a ninguna de las religiones positivas, porque todas ellas han pretendido convertirla en instrumento de sus empresas de dominación, apartándola de sus naturales destinos; haciendo que la que está destinada por la Naturaleza para ser flor perfumada y bellísima, que llene de alegría la vida del hombre, se convierta en rama seca, rodeada de espinas punzadoras, que es preciso huir.

Otro de los medios poderosísimos para influir en la dignificación de la mujer, es el confesionario. Y os hablamos de esto sin prevenciones ni animosidades, con la tranquilidad y la calma de quien no se deja influir por el espíritu de oposición.

La mujer sirve hoy del más firme puntal a la Iglesia, y en su lento pero seguro desquiciamiento, os dice: que la mujer ha de ser piadosa, y os convierte en instrumento dócil en sus manos, en sus principios os insulta, más tarde establece sacramentos como el de la confesión, para “bucear” vuestras almas, y en su agonía, os lleva a los mitins para que aplaudáis sus actos en pro del obrero. Así quiere la teocracia que seáis las mujeres; así os trata; de esa manera os dignifica. ¿No es verdad que la mujer debe grandes cosas al ideal religioso ${ }^{12}$

11 El Liberal, (13-02-1905). Esta misma imagen nos la traslada Luz Santfeliú para el republicanismo blasquista: Los varones que acudían a los casinos eran llamados correligionarios. De las mujeres se resaltaba simplemente su presencia. Ellas, en esos años que comenzaba a ser mayor la difusión de la vida social, siempre eran bellas, hermosas o alegres y contribuían a dar a las celebraciones un matiz diferente, que consistía en hacer que los actos fueran más brillantes. En este tiempo, también, algunas mujeres tomaban la palabra esporádicamente y figuraban entre los oradores que se dirigían a los asistentes. Fuente: SANFELIU GIMENO, Luz: Republicanas. Identidades de género en el blasquismo (1895-1910), Valencia, Universitat de València, 2005, p. 134.

12 El Norte, (18-05-1915). 
Posteriormente, establecían que la educación era necesaria para que las mujeres se librasen del yugo clerical, animándolas a asistir a mítines y conferencias instructivas para así influir en sus maridos de forma positiva:

De todos es sabido que la mujer es el principal agente colaborador del clericalismo, y que de ella se sirven los neos para sus fines, aunque lleven la discordia al seno de las familias. Pues bien: así como ellos se valen de la mujer, sirvámonos también nosotros de ella para combatirlos, educándolas en nuestras ideas liberales, haciéndolas ver que pueden ser creyentes sin ser fanáticas y que pueden practicar la verdadera religión de Cristo sin ser instrumento inconsciente de quienes tienen puestos sus amores en los bienes temporales, mientras predican las excelencias de los espirituales.

Esta labor de educación liberal, comprendo que será algo difícil, pero no imposible, y si los liberales quieren de veras que la libertad brille espléndida, no tienen que hacer más que educar a sus mujeres y a sus hijas, sobre todo a estas últimas por ser mujeres del porvenir, en la forma descripta. ${ }^{13}$

Los españoles no han sabido educar a las mujeres; no han sabido hacerlas partícipes de sus trabajos y de sus luchas; no han sabido humanizarlas, secularizarlas.

Han dicho: para nosotros, la calle; para ellas, el hogar. Y el hogar vence, no por sus virtudes, ni por sus sentimientos, desgraciadamente, sino por la perfidia y la hipocresía.

Mientras en el progreso no entre de lleno la mujer y lo adorne y lo embellezca, el progreso no existirá.

¿Sois revolucionarios? ¿Queréis determinar una transformación social? Conquistad a las mujeres ${ }^{14}$

Esta necesidad de educación femenina no traía directamente consigo una emancipación de la mujer en sentido político, ya que el papel que tenían destinado los republicanos para ellas era el cuidado del hogar y la educación de sus hijos en valores liberales, nunca el de entrar en política, al menos en esta época:

La mujer está sometida a un régimen de fuerza del que es necesario redimirla. Pero redimirla, si. Es el hombre el que debe despojarse de cierta incultura, de cierta brutalidad deprimente para la mujer.

La mujer, rebelándose, no puede conseguir nada. El pueblo fuerte, el pueblo en mayoría, empujado por la fuerza de la necesidad, ha estado y continúa empeñado en hacer prevalecer sus derechos. Y estos esfuerzos, de una fuerza y una resistencia inagotable, consiguen lentamente el imperio del derecho.

Mal pueden, pues, las mujeres, llegar a imponerse por el terror. El esfuerzo de las sufragistas tiene que ser esfuerzo perdido. No abonamos nosotros por la mujer política.

13 El Liberal, (11-12-1906).

14 BAROJA NESSI, Pío: “La secularización de las mujeres”, El Norte, (06-12-1915). 
Nos encanta, sí, oír llamarse a las mujeres, republicanas, o vizcaitarras, o carlistas, porque los más queridos de los suyos lo fueron. Esto es una supervivencia del cariño, delicado aroma femenino que debiera guardarse en ánforas cinceladas, para poderlo escanciar en las copas de los luchadores si alguna vez sentimos el desfallecimiento en la lucha.

La mujer, sí, debe tener una aspiración platónica. Recoger las necesidades populares y forjar un ramillete de deseos. Alentar al hombre que se deja influir por su palabra.

Pero la lucha política destila podredumbre o sangre. Y no queremos nosotros que la mujer llegue a inficionarse, o que caiga apuñalada en la arena del palenque.

No. La mujer debe cultivar, sí, esa aspiración instintiva al bienestar; rebelarse contra toda imposición; dorar con matices de ensueño la visión del porvenir; enjugar el sudor de los que luchan; alentar a los que vacilan; sonreír a los que triunfan; cerrar los ojos y llorar por los que mueren.

Pero nada más. La lucha política quitaría a la mujer el encanto de la sugestión. Bien vemos que en la pequeña actuación que desempeñan, son instrumento de los hombres pérfidos, encubiertos de carátula evangélica ${ }^{15}$.

En la II República, con el reconocimiento de todos los derechos civiles y políticos para la mujer, su imagen y papel dentro del republicanismo cambió totalmente con respecto a lo visto en la Restauración. Las mujeres pasaron de figurar como acompañantes en las actividades de los casinos a engrosar las filas de los partidos políticos como militantes de los mismos casi al mismo nivel que sus compañeros masculinos, para lo cual las diversas formaciones políticas y grupos juveniles organizaron secciones y grupos femeninos, a la vez que se formaron asociaciones de mujeres autónomas al margen de la disciplina de los partidos.

El discurso que se mantiene en esta época con respecto al papel de la mujer en el republicanismo mantiene semejanzas y discontinuidades con el período anterior. Por una parte, todavía se lastraba la concepción de que la mujer había estado esclavizada hasta entonces por la concepción clerical de la sociedad; así se expresaba el dirigente republicano local, y destacado masón, Ambrosio Garbisu Pérez ${ }^{16}$ :

Con un brillante exordio se refirió a la esclavitud en que hasta nuestros días ha vivido la mujer, sujeta a la vigilancia inquisitiva de sus menores movimientos, sobre los que cualquiera se consideraba autorizado a formular juicio y aún a calificar con excesiva ligereza y sin responsabilidad.

Agrega que, habiendo coincidido la invitación con la fecha del viernes santo, pronunciaría sus siete palabras sobre la pasión, muerte y resurrec-

15 RANZ LAFUENTE, Daniel: “La mujer política”, El Norte, (06-12-1915). Daniel Ranz ejercía en esos momentos la responsabilidad de profesor del Centro de Enseñanza Libre de la calle Ronda de Bilbao, una escuela laica vinculada al republicanismo.

16 Ambrosio Garbisu en ese momento era Teniente Alcalde del Ayuntamiento de Bilbao, jefe de la minoría municipal de Acción Republicana y Venerable Maestro de la logia masónica Goethe ${ }^{\circ} 2$ de la capital vizcaína. 
ción de la mitad del género humano, que comprende a la mujer de todo el mundo, pero sobre todo a la mujer española, que es la más influida y acosada, por toda clase de prejuicios sociales. Desde la creación de la humanidad viene la mujer injustamente marcada con el estigma de la impureza, y condenada perpetuamente a sufrir el dolor de la humana generación por el pecado de desobediencia al Creador. La Iglesia, exclama, ha querido después corregir esta cruel consideración, haciendo brotar un Dios de sus entrañas, pero nada ha hecho en la práctica de su apostolado, con trascendencia eficaz para levantarla del deshonor en que la colocó el falso concepto de una moral puramente fisiológica, sin nexo ni relación con los atributos de la conciencia, que es la que discierne en la materia ${ }^{17}$.

Por otra parte, para atraerse al elemento femenino al campo republicano o izquierdista, se decía a las mujeres que su liberación, los derechos políticos y sociales para ellas, habían llegado gracias a la instauración de la República. Continuamos con la conferencia de Garbisu, porque es excelente para reflejar este parecer:

La mujer, en todos los órdenes de su existencia, ha sido hasta ahora considerada como un instrumento; unas veces de placer, otras de explotación, otras de intriga, y siempre indigna da alcanzar la plena prerrogativa humana. Muerta estaba en este punto si no viene la República a reivindicar para ella derechos que siempre se le negaron, a elevar su condición moral y a darla categoría y personalidad.

Bien podéis decir que habéis resucitado a nueva vida, y que los jalones de vuestra redención están colocados desde que sois ciudadanas de la República. A vosotras os toca saber utilizar los derechos alcanzados, haciendo honor al Régimen que os los concedió y dando un rotundo mentís a quienes todavía os niegan aptitud y voluntad para sentir en toda su magnitud y hondura los problemas que embargan la atención de los hombres ${ }^{18}$.

Este razonamiento de que la República era la responsable de la emancipación de la mujer se repitió constantemente en los momentos previos a las elecciones de Diputados a Cortes de 1933, en las que la mujer ejercía el derecho de sufragio por primera vez. La intención era clara, atraerse el voto femenino a toda costa por el miedo que existía a que la mujer votase a la derecha debido a la visión catastrofista que estaba ofreciendo ésta sobre la legislación en materia religiosa de la República, para lo cual se insistía en que la República había elevado la condición moral de la mujer y la había otorgado derechos, por lo que debía votar a las izquierdas como muestra de agradecimiento ${ }^{19}$ :

17 El Liberal, (15-04-1933). Conferencia pronunciada en la Unión Femenina Republicana.

18 Ibidem.

19 Pablo Villalaín nos cuenta como en Madrid la campaña electoral de organizaciones como Unión Republicana Femenina y Agrupación de Mujeres Republicanas se basó en el agradecimiento al régimen republicano por la concesión a la mujer de sus derechos civiles y políticos, y la necesidad de colaborar con su voto femenino en el triunfo de las organizaciones que lo hicieron posible. Fuente: VILLALAÍN GARCÍA, Pablo: "La participación de la mujer en las elecciones generales celebradas en Madrid durante la II República”, Arenal. Revista de Historia de las mujeres, 4-2 (1997), pp. 308-309. 
¿Qué debes a la República? La República ha hecho de ti un ser libre con personalidad jurídica, colocándote a la altura del hombre y dándote los medios de que puedes utilizar tu inteligencia y tu energía, colaborar, no sólo para el engrandecimiento de tu patria, sino para buscar la definitiva redención a la que tienes derecho.

La República, al concederte el voto, se ha puesto en íntima relación con tu conciencia, y ello te obliga a interesarte por los problemas públicos y a darte cuenta de que el Dios en quien crees no te forjó un alma ni te dio un cerebro por la ignorancia o el egoísmo de los demás, sino por los propios dictados de tu libre albedrío.

La República, al legislar en materia religiosa, no ha herido tu conciencia, sino que ha dejado en pie toda la organización litúrgica que tú necesitas para cumplir los deberes de tu religión.

Puedes hacer religiosamente tu matrimonio, el bautizo de tus hijos, el entierro de tus deudos fallecidos, y puedes seguir oyendo la misa, haciendo tus confesiones y comuniones y acudiendo a los ritos religiosos que desees. Lo único que ha hecho la República, siguiendo el ejemplo de todas las Repúblicas y monarquías, es separar la iglesia del Estado, haciendo que pague el culto aquel que lo utilice, y respetando el derecho de los no católicos, que es tan digno de atención como el de los que siguen el dogma. La República, en suma, no ha hecho más que seguir el precepto de dar a Dios lo que es de Dios y al César lo que es del César ${ }^{20}$.

Mujer trabajadora! Por primera vez vamos a participar las mujeres en las luchas políticas del país gracias a la República.

Tú, mujer, si eres madre, por tus hijos; si no lo eres, por tus padres y por tus hermanos, que sufren el hambre y la miseria, producto de la sociedad burguesa, debes aprestarte a impedir que el dolor siga atenazando a los tuyos. La mejor ocasión se te presenta con motivo de las elecciones del día 19 votando la candidatura integrada por republicanos y socialistas (...)

(...) Frente a todas las fuerzas de derecha se levanta la de las socialistas y republicanos, que son los que han de establecer mejoras para todos los trabajadores (...)

(...) Por la República somos cada vez más libres y debemos hacer todo lo posible porque, al igual que hacen los demás obreros, nos alcancen las leyes sociales, incluso la de Jurados mixtos, para desde ellos establecer las bases de trabajo que regulen la jornada y el sueldo.

Si votáis a los vizcaitarras, carlistas y demás enemigos de los obreros, en lugar de mejorar estaréis peor.

Mujeres: ¡Por vuestro bien, votad a la candidatura republicanosocialista! ${ }^{21}$ 
A pesar de querer contar su apoyo electoral, los republicanos bilbaínos cifraban el papel político de la mujer no tanto en la primera línea de la actividad política, como en tareas benéficas y de acción social y, sobre todo, como madres de las futuras generaciones republicanas, sosteniendo por tanto un concepto maternalista de la mujer de la misma forma que en las dos primeras décadas del siglo XX:

Marca la trayectoria que ha de seguir la mujer en las actividades de la política y de la función social, adecuándola a la beneficencia, a la dulcificación de los procedimientos de lucha como reguladora del impulso masculino, a la concordia, y sobre todo a la formación de nuevas generaciones de hombres, en su altísima función maternal, que es para lo que la República quiere capacitarla dotándola de una cultura y poniendo a su disposición los medios de alcanzarla ${ }^{22}$.

Terminó abogando por una España grande, enaltecida por las virtudes de la mujer republicana, que sabrá inculcar a sus hijos el espíritu de ciudadanía, formando verdaderos hombres para engrandecimiento de España ${ }^{23}$.

\section{Centros de sociabilidad femenina en Bilbao}

La única asociación femenina creada en Bilbao durante las dos primeras décadas del siglo XX fue la Agrupación de Damas Rojas ${ }^{24}$, a instancias del Partido Republicano Radical. Se trataba de un grupo de mujeres que venía a hacer la competencia a las agrupaciones femeninas católicas, dentro del conflicto clericalismo/anticlericalismo que estaba sacudiendo la política nacional. El 16 de mayo de 1910 se anunciaba en El Liberal la inminente organización de la citada agrupación en la misma forma en que estaba establecida en otras capitales españolas, a las que se las había pedido sus reglamentos para formalizar los propios ${ }^{25}$. En la gacetilla se añadía que con la creación de este grupo

\footnotetext{
22 El Liberal, (15-04-1933).

23 El Liberal, (13-05-1933).
}

24 Las Damas Rojas nacieron en Barcelona en 1908 vinculadas al radicalismo, tomando ejemplo de otras asociaciones femeninas laicas que existían en la ciudad, como la Sociedad Progresiva Femenina fundada por Ángeles López de Ayala. Las Damas Rojas tenían su sede principal en la Casa del Pueblo y tenían filiales en los barrios obreros; sus socias eran, en su mayoría, obreras analfabetas, y sus actividades estuvieron marcadas por un notable anticlericalismo. Sus excesos en este sentido hicieron que una parte de ellas, provenientes de la clase media y con un nivel educativo mayor, se separaran para crear el grupo Damas Radicales, más preocupado por la educación laica. Fuentes: RAMOS PALOMO, M $^{\mathrm{a}}$ Dolores: "Hermanas en creencias, hermanas de lucha. Mujeres racionalistas, cultura republicana y sociedad civil en la Restauración”, Arenal. Revista de Historia de las mujeres, 11-2 (2004), pp. 27-56. RUIZ MANJÓN, Octavio: El Partido Republicano Radical 1908-1936, Madrid, Tebas, 1976, pp. 643-644.

25 No disponemos de los estatutos de las Damas Rojas bilbaínas, aunque suponemos que no diferirían en demasía de los de la agrupación barcelonesa, en los que se recogía que la finalidad del grupo era "propagar entre las mujeres los ideales de la Libertad y de República y de auxiliarse y socorrerse mutuamente las asociadas en sus necesidades, y auxiliar y socorrer a los correligionarios que por defender estos ideales sufran cualquier clase de perjuicios, así como las familias de estos”. Citado en DEL MORAL VARGAS, Marta: “Acción colectiva femenina republicana: Las Damas Rojas de Madrid (1909-1911), una breve experiencia política”, Hispania, Revista Española de Historia, 226 (2007), pp. 541-556. 
las señoras de la Liga y demás agrupaciones femenino reaccionarias, encontrarán un gran enemigo que las combate con la luz de la verdad ${ }^{26}$.

Un mes después se formaba una comisión, compuesta por seis mujeres, encargada de realizar los trabajos preliminares para la constitución de la sociedad, cuyo objetivo sería el de auxiliar y socorrer a los presos y perseguidos por cuestiones políticas y sociales, y dar batalla en toda línea a las mujeres reaccionarias ${ }^{27}$.

A lo largo del mes de julio quedó formada la Junta Directiva de la agrupación ${ }^{28}$, a la que acompañaría un asesor nombrado por la Junta Municipal del partido y se aprobó su reglamento ${ }^{29}$, mientras que en el mes de agosto se daban por terminados los trabajos preliminares para la formación de las Damas Rojas en Bilbao, anunciando que la componían más de cien mujeres ansiosas de ejercer la caridad con todo ser desvalido y necesitado, sin ejercer influencias en sus sentimientos y en su manera de pensar, como hacen todas las Agrupaciones de verdaderas damas católicas ${ }^{30}$.

Para ingresar en la Agrupación de Damas Rojas era necesario disfrutar de buena reputación y amoldar sus actos y costumbres a la moral y conducta que cada uno debe a sus semejantes, y ser presentada por dos asociadas que respondiesen de los buenos antecedentes de la solicitante. Las asociadas debían pagar una cuota mensual, que se fijó en 25 céntimos.

En el tiempo en que estuvieron activas las Damas Rojas llevaron a cabo algunas iniciativas que nos dan idea de la finalidad para la que fueron creadas. En julio de 1910 acordaron dirigir un mensaje al Presidente del Consejo de Ministros protestando de la representación que se arrogaban las Damas católicas de todas las mujeres españolas, a la vez que invitaban al Gobierno a seguir la campaña contra el clericalismo y le pedían más reformas anticlericales ${ }^{31}$. Las Damas Rojas exhortaban a todas las mujeres liberales bilbaínas a que suscribieran dicha protesta y adhesión a la campaña anticlerical, para lo cual muchas mujeres pasaron los siguientes días por el Centro Radical de la bilbaína calle Barrencalle Barrena para estampar su firma al pie del mensaje ${ }^{32}$.

Por otro lado, las Damas Rojas organizaron veladas teatrales benéficas en colaboración con los grupos artísticos socialista y republicano cuyos beneficios se destinarían al socorro de los obreros en huelga y sus familias ${ }^{33}$.

26 El Liberal, (16-05-1910).

27 El Liberal, (15-06-1910).

28 El Liberal, (09-07-1910). La Junta la formaban: presidenta Julia Conde, vicepresidenta Benita S. Martínez, secretaria Ester Martínez, vicesecretaria Josefa Lombardera, tesorera Isabel Yuste, contadora Dionisia Martínez, vocales Isabel Vila, Justa Martínez y María Cantera. Unos días más tarde se facilitó a la prensa una nueva composición: presidenta Julia Conde, vicepresidenta Ester Martínez, secretaria Rosa Erce, vicesecretaria Mercedes Pérez, tesorera Isabel Yuste, contadora Antonia Méndez, vocales Sofía Ladredo, Justa Martínez y María Cantera.

29 El Liberal, (21-07-1910).

30 El Liberal, (22-08-1910).

31 El Liberal, (05-07-1910). El motivo de esta reacción fue que a finales de junio de 1910 un grupo de mujeres aristocráticas se dirigió a Canalejas para protestar por las reformas laicas que pretendía introducir el gobierno, organizando paralelamente manifestaciones, mítines y rezos colectivos.

32 Protestas y manifestaciones en contra de la actuación de las mujeres católicas y de la influencia del clero en la sociedad y en la política se reprodujeron por muchas ciudades españolas. Ver DEL MORAL VARGAS, Marta: “Acción colectiva femenina republicana...”, op. cit., pp. 557-562.

33 El Liberal, (06-08-1910). 
No sabemos la fecha concreta de la definitiva disolución de la Agrupación Damas Rojas ${ }^{34}$; las noticias son prolijas en 1910, mientras que en 1911 sólo encontramos una noticia relacionada con ellas en el mes de noviembre sobre la entrega de documentación y objetos por parte del asesor del partido a la agrupación por tener éste que trasladarse a otro lugar. Creemos que tras las actividades desarrolladas en 1910, el grupo estuvo bastante inoperativo a partir de entonces, a lo que tampoco colaboraría la posición minoritaria en que se encontraba el Partido Radical en el panorama político bilbaíno. No obstante, las Damas Rojas fueron la primera asociación femenina republicana establecida en Vizcaya, y nos sirven para analizar la relación entre mujer, republicanismo y laicismo en esta época de conflicto entre clericales y anticlericales.

Por lo que respecta al asociacionismo femenino en la II República en la Villa de Bilbao, éste estuvo reducido entre 1931 y 1932 a los Grupos Femeninos de los partidos políticos y de la Juventud Republicana, mostrándose los mismos bastante inactivos en cuanto a la promoción de actividades destinadas a la mujer. Cabe destacar únicamente la labor de la Juventud Republicana en este sentido, pues organizó un ciclo de conferencias expresamente dedicado al público femenino y un concurso de labores, todo ello con la finalidad de estimular a la mujer a frecuentar los locales de la sociedad, interesarla en la política, y librarla de los prejuicios seculares ${ }^{35}$.

No fue hasta la fundación de la Unión Republicana Femenina ${ }^{36}$ a finales de 1932 cuando la presencia de la mujer republicana en la vida pública bilbaína se hizo presente, pues hizo desaparecer al resto de agrupaciones femeninas de partido y de juventud, de las que hablábamos antes, para congregar en torno a sí a todas las mujeres republicanas sin distinción de matices ${ }^{37}$. Era el despertar de la mujer republicana bilbaína, tal y como rezaba el título de un suelto en el diario El Liberal:

Esto es lo que habéis hecho vosotras, mujeres bilbaínas. Llevabais dentro de vuestro corazón el sentir demócrata porque lo heredasteis de vuestras madres y abuelas, de aquellas valerosas mujeres de los años 74 y 36, que con su alegría y entusiasmo dieron aliento a los hombres que luchaban contra la reacción y la tiranía, y contribuyeron a su triunfo.

Pues bien, aquel sentir demócrata ha estado dormido durante muchos años, pero hoy despierta, resurge con el mismo entusiasmo de entonces,

34 Culla i Clara dice que todos los grupos de Damas, al menos los de Barcelona, y suponemos que con ellos los del resto de ciudades españolas, fueron sacrificados por Lerroux en un drástico decreto de disolución en julio de 1911. CULLA i CLARA, Joan B.: El republicanismo lerrouxista a Catalunya (1901-1923), Barcelona, Curial, 1986, p. 429.

35 El Liberal, (06-02-1932).

36 La Unión Republicana Femenina fue fundada en noviembre de 1931 por Clara Campoamor como organización política cuyo fin primordial era preparar a la mujer para el ejercicio de sus deberes cívicos, activos y pasivos en defensa de la República mediante cursos y conferencias sobre temas políticos y de cultura en general, prácticas directas de propaganda y organización. Fuente: AGUILERA SASTRE, Juan: “1931: Las mujeres españolas ante la República”, Cuadernos Republicanos, 64 (2007), pp. 126-127. Un buen acercamiento a la biografía de Clara Campoamor en FAGOAGA, Concha. y SAAVEDRA, Paloma: Clara Campoamor. La sufragista española, Madrid, Instituto de la Mujer, 2007.

37 Cuando hablamos de que las demás agrupaciones femeninas vinculadas a partidos o a organizaciones juveniles desaparecieron lo decimos en sentido estricto, pues desde la creación de la Unión Republicana Femenina no volvemos a tener referencias de la vida del resto de agrupaciones femeninas, por lo que creemos que la fundación de la Unión constituyó el fin de todas ellas. 
y la prueba indiscutible es que al llamamiento hecho por un puñado de mujeres republicanas han respondido en cinco meses cientos de mujeres, hasta pasar del millar, y ha nacido "Unión Republicana Femenina”, pletórica de ansias de renovación, de justicia, de abnegación y de amor a sus semejantes; de deseos de infiltrar en los corazones la unión y la paz y, en fin, de colaborar por la República, para que España sea la nación ejemplar y próspera a que tiene derecho ${ }^{38}$.

La URF se constituyó en Bilbao el $1^{\circ}$ de diciembre de 1932 en el transcurso de una asamblea, celebrada en la Sociedad El Sitio, en la que se aprobaron sus estatutos y reglamento, y se eligió a su primera Junta Directiva. La URF venía, decían, a llenar el vacío que se dejaba sentir en Bilbao debido a la desunión existente en el elemento femenino que comulga con nuestros ideales, sintetizados en el lema igualdad, libertad, fraternidad ${ }^{39}$.

Si bien en los primeros meses de existencia de la sociedad ésta se instaló provisionalmente en los locales de la citada Sociedad El Sitio, en marzo de 1933 la URF procedió a la inauguración de su propio domicilio social, situado en la calle Banco de España $n^{\circ} 3$ primero derecha. El inmueble estaba compuesto, entre otras dependencias, por un amplio salón de actos, la sala de juntas, el salón biblioteca y una sala destinada a los niños de las afiliadas ${ }^{40}$.

Entre las actividades pedagógicas que la URF promovió destacaron sobremanera la organización de conferencias, cuyos temas versaron fundamentalmente sobre el papel de la mujer en la II República y sobre cuestiones políticas de actualidad, que impartían personajes de todo tipo, tanto hombres como mujeres, y tanto bilbaínos como foráneos. Aparte de las conferencias, la URF organizó clases y cursos de utilidad para la mujer, con asignaturas como corte de ropa, bordados, repujado, música, matemáticas, idiomas o artes decorativas, y recitales de música y poesía.

Entre las actividades políticas que desarrolló la URF cabe destacar la organización de mítines electorales, sobre todo de cara a las elecciones de Diputados a Cortes de 1933 con la finalidad de convencer a la mujer bilbaína para que votase a las izquierdas, la celebración del aniversario de la República de 1873, y la participación, desde 1933, en las actividades del 2 de mayo ${ }^{41}$. Merece la pena detenerse en esto último, pues en la historia de las celebraciones del 2 de mayo bilbaíno no fue hasta la creación de la URF cuando por primera vez tomó la palabra una mujer en los discursos de homenaje a los caídos en la defensa de los sitios de Bilbao:

38 El Liberal, (11-04-1933).

39 El Liberal, (06-12-1932). La primera Junta Directiva de la URF la compusieron: presidenta Sra. de Guibelondo, vicepresidentas Adoración García y Virginia M. del Castillo, secretaria Luisa Fatrás, vicesecretarias Elisabeth Palomo e Irene Corraleche, contadora Trinidad Miranda, bibliotecaria Isabel Gorriarán, vocales Dolores Bravo, Aurelia Vega, María R. de Cía, María Gardiazabal, Victorina Vela, y Teresa Antón.

40 La inauguración de los locales de la URF en El Liberal, (26-03-1933).

41 Cada 2 de mayo se celebraba en Bilbao, por parte de liberales y republicanos, el levantamiento del sitio carlista de 1874. La fiesta consistía en una procesión cívica desde el Casco Viejo hasta el cementerio de Mallona, donde delante del monumento dedicado a los héroes de la libertad de 1874 se pronunciaban varios discursos por diferentes representantes políticos. Esta fiesta, mucho menos multitudinaria, se celebra todavía hoy en día promovida por la Sociedad El Sitio. 
Hasta ahora a la mujer no se le había concedido intervención oficial en el homenaje de respeto y gratitud que anualmente viene el pueblo de Bilbao rindiendo a estos héroes, y aunque todos sabéis que en espíritu siempre estuvo aquí presente, su alegría no tiene hoy límites al poder hacerlo personalmente y decirles: La libertad que defendisteis a costa de vuestras vidas ha triunfado y ha llegado también para la mujer, para aquella mujer que compartió con vosotros las penalidades de los sitios y que como vosotros vertió su sangre; para aquella mujer que nuestros enemigos querían seguir teniendo esclavizada y separada de la vida política, como si la política no representara para ella nada, como si no representara el bienestar y la felicidad de sus hijos ${ }^{42}$.

A pesar de que la Unión Republicana Femenina de Bilbao se declaró desde un principio como una organización autónoma y no dependiente de ninguna otra entidad, en enero de 1935 se definió políticamente por Izquierda Republicana, pasando a conformarse de algún modo como la sección femenina de dicho partido, pero manteniendo, eso sí, toda su autonomía organizativa.

Otra asociación femenina vinculada al republicanismo fue la Fraternidad de Mujeres Modernas, creada en 1932 en el barrio bilbaíno de Torre-Urizar, y que posteriormente se fue extendiendo por el resto de la Villa. El objeto con el que se creó la misma fue el de fomentar la fraternidad entre las mujeres vecinas de Torre-Urizar, primero, y de todo Bilbao, después; defender y proteger los derechos políticos, jurídicos y sociales de la mujer; reunir fondos para festejar las fiestas del 14 de abril y 1 y 2 de mayo; recabar mejoras para el barrio de Torre-Urizar y otros en donde se constituyeran secciones de la asociación; atender a la labor de cultura familiar, política y social de las afiliadas y sus familias por medio de conferencias, libros, folletos y circulares; y crear un fondo especial para atender a las necesidades de alguna afiliada en apuros. Todos los actos de la asociación, decían, se significarían por su carácter liberal y laico ${ }^{43}$.

La Fraternidad de Mujeres Modernas creó en su seno grupos de espatadantza e hilanderas, con el fin de atender a la educación física del niño y presentarlos en las fiestas que realizase el grupo, y tenía previsto en sus estamentos la posibilidad de crear una sección que tratase de asuntos de cultura familiar, política y social, etc. ${ }^{44}$.

\section{Conclusiones}

Es a partir de 1903 cuando detectamos la presencia de la mujer en actos promovidos por el republicanismo. Desde esa fecha hasta 1923, el papel de la mujer se reduce prácticamente a la asistencia a actos celebrados en los centros de sociabilidad republicanos, tales como bailes, veladas y conferencias.

La imagen que se traslada de la mujer es de un sujeto subyugado por el clericalismo, que sólo se libraría de esa perniciosa influencia a través de la educación. La tarea

42 El Liberal, (03-05-1933).

43 AGGC-IRARGI, Rollo 239, Caja 31, Expediente nº 1.

44 AGGC-IRARGI, Rollo 239, Caja 255, Expediente nº 3. 
que reservan los republicanos en esta época a la mujer es el cuidado y la educación de los hijos, los futuros ciudadanos.

En la II República, con el reconocimiento de derechos a la mujer, las mujeres pasaron a ser sujetos activos en la política republicana. En este momento, los republicanos se quieren atraer el apoyo femenino a su causa dejando claro a las mujeres que la consecución de todos sus derechos civiles, sociales y políticos había sido sólo posible gracias a la República, mientras que si votaban a la derecha volverían a estar sometidas.

Únicamente tenemos constancia de la formación de una agrupación republicana femenina en las dos primeras décadas del siglo XX, la de las Damas Rojas que, vinculada al Partido Radical, estuvo poco tiempo en activo.

Las organizaciones femeninas durante los dos primeros años de la República estuvieron vinculadas a los partidos políticos y se mantuvieron poco activas, no siendo hasta la creación de la Unión Republicana Femenina cuando la presencia de la mujer en el ámbito político bilbaíno se dejó notar. 